\title{
Avanços e retrocessos das licenciaturas da área de ciências da natureza
}

\author{
Advances and backdrops of teacher training courses in natural sciences area \\ Avances y retrocesos de las titulaciones en el área de ciencias naturales
}

\section{Resumo}

As políticas públicas educacionais relacionadas à formação inicial de professores têm assumido uma centralidade no campo que tange às pesquisas educacionais. Neste quesito, analisamos os Projetos Pedagógicos do Curso (PPC) com objetivo de identificar avanços e retrocessos na formação inicial de licenciandos em Ciências Biológicas, em Química e em Física da Universidade Federal de Santa Maria, campus Santa Maria/RS, em relação às Diretrizes Curriculares Nacionais (DCN) para a formação de professores. Utilizamos como metodologia pesquisa qualitativa, documental e descritiva, e empregamos como método de análise a Análise de Conteúdo. A partir dos resultados encontrados, percebemos que o Estágio, a Prática como Componente Curricular (PCC), a Atividade Complementar e a Carga Horária total do curso estão, em grande parte, em consonância com as legislações que orientam as Resoluções CNE/CP N. 01/2002, 02/2002 e 02/2015. Todavia os cursos encontram-se em descompasso quanto à BNC-Formação orientada na Resolução CNE/CP N. 02/2019. Dessa forma, inferimos que incentivar o desenvolvimento de um PPC melhor e diversificado, poderá caminhar para uma formação de professores em direção ao perfil esperado.

Palavras-chave: Formação de professores; Projeto pedagógico de curso; Licenciatura em ciências biológicas; Licenciatura em física; Licenciatura em química; Ensino.

\begin{abstract}
Educational public policies related to initial teacher training assumed a centrality in the field that concerns educational research. We analyzed the Pedagogical Projects of Courses (PPC) aiming to identify advances and setbacks in teacher training in Biological Sciences, in Chemistry, and in Physics at the Universidade Federal de Santa Maria, campus from Santa Maria/RS, in relation to the National Curriculum Guidelines for teacher training. We carried out a qualitative, documentary, and descriptive research using content analysis as analysis methodology. From the results found, we realized that the Internship, Practice as a Curriculum Component, Complementary Activity and Total Credit Hours of the courses are, for the most part, in line with the laws that guide CNE/CP Resolutions N. 01/2002, 02/2002 and 02/2015. However, the courses are out of step with the BNC-Training guided by Resolution CNE/CP N. 02/2019. Thus, we infer that encouraging the development of a better and diversified PPC may lead to teacher training towards the expected profile.
\end{abstract}

Keywords: Teacher training; Pedagogical course projects; Biology graduation; Physics graduation; Chemistry graduation; Teaching.

\section{Resumen}

Las políticas públicas educativas relacionadas con la formación inicial del profesorado han adquirido un papel central en el campo de la investigación educativa. En este sentido, analizamos los Proyectos Pedagógicos de los Cursos (PPC) con el objetivo de identificar avances y retrocesos en la formación en Ciencias Biológicas, en Química y en Física de la Universidade Federal de Santa María, campus Santa Maria/RS, en relación a los Lineamientos Curriculares Nacionales para la formación docente. Realizamos una investigación cualitativa, documental y descriptiva mediante análisis de 
contenido como metodología de análisis. A partir de los resultados encontrados, nos dimos cuenta de que la práctica, la práctica como un componente curricular, la actividad complementaria y el total de horas de crédito del curso están, en su mayor parte, en línea con las leyes que rigen las Resoluciones CNE/CP N. 01/2002, 02/2002 y 02/2015. Sin embargo, los cursos están desfasados con el BNC-Formación guiado por la Resolución CNE/CP N. 02/2019. Fomentar el desarrollo de un PPC mejor y diversificado puede conducir a la formación del profesorado en dirección al perfil esperado. Palabras clave: Formación de profesores; Proyecto pedagógico del curso; Graduación en ciencias biológicas; Graduación en física; Graduación en química; Enseñanza.

\section{Apontamentos Históricos da Formação de Professores no Brasil}

As políticas públicas educacionais direcionadas à formação de professores, em especial, à formação inicial, têm assumido centralidade no campo de pesquisas educacionais. Destacamos preocupações com os encaminhamentos e direcionamentos que as reformas educacionais, nos últimos anos, repetidamente, têm projetado e formatado os moldes dos futuros professores no Brasil.

Há uma complexidade por trás da estrutura das reformas curriculares para a formação de professores, uma vez que, com o processo de globalização e ramificação de políticas neoliberais no contexto educacional brasileiro, a tendência de se "alinhar" às políticas, no formato de um grande "pacote educacional", é cada vez mais expressivo. Nesse sentido, com o objetivo de atender às demandas internacionais, as políticas curriculares, tanto da Educação Básica quanto do Ensino Superior, de avaliação e de material didático, caminham de mãos dadas para uma tendência de padronização/ estandardização do ensino (Lopes et al., 2021).

Contextualizar as múltiplas influências presentes nas mais recentes produções de políticas curriculares no país, nos coloca frente a novas perspectivas e olhares sobre os diferentes atores que atuam nessa produção. Bem como, coloca luz às diferentes demandas emergentes dessas novas propostas que são (re)formuladas no âmbito de intensas disputas políticas e de poder nas diferentes arenas de luta.

Um processo de análise minucioso nos permite compreender como essas políticas são produzidas e que discursos sobre o currículo para a formação de professores estão presentes. Além disso, entender quais influências e contextos externos impactam as políticas educacionais nacionais como o cumprimento da Agenda 2030 da Organização das Nações Unidas (ONU) em paralelo a uma Agenda Nacional proposta a partir do Plano Nacional de Educação (PNE 2014-2024). Tais compromissos e acordos firmados remetem a discussões para além dos espaços de produção de políticas curriculares nacionais.

De acordo com Amestoy, Rigue e Gonçalves:

O currículo das instituições brasileiras tem sido um campo fértil de intensas disputas, no qual protagoniza importante papel de governamento social, político, econômico e cultural. A intensidade dessas disputas está diretamente relacionada com a complexidade que permeia a elaboração e implementação de um currículo nacional, mas também pela extensão territorial do Brasil - seus estados e municípios. (Amestoy, Rigue \& Gonçalves, 2021, p. 175).

A organização curricular dos cursos nas instituições, ou seja, as disciplinas que possibilitam a consolidação do profissional a ser formado são expressos nos Projetos Pedagógicos de Curso (PPC). Esses, representam o planejamento estrutural e funcional, em que são delineados diversos atributos aos cursos (objetivos, metodologias, avaliação, recursos humanos e infraestrutura, dentre outros).

No Brasil, os primeiros cursos de formação de professores foram criados nas Faculdades de Filosofia, Ciências e Letras na década de 1930, buscando atender à demanda criada no Brasil. Neste período, o país tornava-se cada vez mais urbano e industrializado, no qual reivindicavam oportunidades educacionais para a sociedade civil como um todo.Use o parágrafo como modelo. 


\section{Resgate Histórico dos Cursos da Área da Ciência da Natureza}

Com a reforma no sistema educacional ocorrida em 1931, as disciplinas de caráter científico como Biologia, Física e Química, passaram a ser obrigatórias na educação secundária. Além disso, foi exigido que os professores atuantes nesse segmento, fossem licenciados pelas faculdades recém criadas. Para atender a esta demanda, as primeiras experiências de formação de professores em ensino superior ocorreram no Instituto de Educação de São Paulo e no Instituto de Educação do Distrito Federal nos anos 1930. Contrários ao projeto de educação tradicional, Fernando de Azevedo e Anísio Teixeira que encabeçaram esses espaços, reivindicavam uma educação democratizadora, segundo os princípios liberais. Apresentamos, a seguir, um breve relato histórico desses cursos.

A história de formação de professores em Ciências e Biologia no Brasil é consideravelmente recente dentro do contexto educacional, sendo marcada pelo contexto social e político de cada período histórico do país. Medeiros e Medeiros (2020) afirmam que cada período histórico determinou um tipo de ensino e, consequentemente, definiu diferentes perfis de professores, modelos de currículos e de formação docente.

Dentro desse panorama, a formação de professores nessa área teve seu início em 1934, na Faculdade de Filosofia da Universidade de São Paulo e posteriormente no mesmo ano, na Universidade Federal do Rio de Janeiro com a denominação de História Natural, a qual permaneceu assim por quase três décadas. O Curso de História Natural, era composto por quatro anos, sendo os três primeiros anos de estudo das disciplinas de Biologia, Química, Física, Geologia, entre outras, e o último ano composto pelas disciplinas de formação profissional, como psicologia educacional, didática geral, organização do ensino secundário, entre outras (Ayres, 2005).

Medeiros e Medeiros (2020) expõem que assim como os demais cursos, o objetivo era a formação de professores para o ensino secundário, equivalente aos anos finais do Ensino Fundamental e Ensino Médio atuais, nos quais o ensino de ciências não era obrigatório. Essa perspectiva só é modificada na década de 1960 quando mudanças significativas ocorrem no campo da formação de professores de Ciências Biológicas e demais áreas, devido à crescente e súbita demanda educacional que o país passava, resultando na carência de docentes nas escolas brasileiras (Lisovski, 2006).

Neste sentido, umas das principais mudanças ocorridas foi a promulgação da Lei de Diretrizes e Bases da Educação (LDB) $n^{\circ}$ 4.024/61 que institui como obrigatório o ensino de Biologia no ginásio e posteriormente, ao ser reformulada, transpõe em 1971, essa perspectiva para o ensino secundário (Krasilchik, 1987). Além disso, em 1963, o curso de História Natural foi extinto originando dois cursos independentes, o de Geologia e o de Ciências Biológicas, sob a justificativa de que a profissão de geólogo já existia independente e previamente a este curso (Tomita, 1990).

Para tanto, em decorrência dessas mudanças e do período social e político dessa fase, Medeiros e Medeiros (2020) destacam o surgimento na década de 1970, das Licenciaturas em Ciências Biológicas de caráter Pleno (quatro anos de duração) e as Licenciaturas Curtas em Ciências (três anos de duração). Esta última, extinta com a promulgação da nova LDB em 1996, originando um novo momento histórico para a formação de professores.

Assim como o curso de Biologia, o curso de Física iniciou-se juntamente à Faculdade Nacional de Filosofia, no qual contava em sua matriz curricular com diversas disciplinas específicas da área, que após a conclusão, os estudantes recebiam seu diploma como bacharel. Caso desejassem, poderiam fazer um curso complementar de Didática, que lhes conferiria o título de Licenciado, instituindo o 'modelo $3+1$ ', sistema em que os três primeiros anos eram dedicados ao estudo dos conhecimentos técnicos-científicos e o último, às didáticas e prática profissional. Com as normas nacionais ocorridas pela LDB/1996 e pelas Diretrizes Curriculares Nacionais (DCN) de 2002, o curso de Licenciatura em Física passa a ocorrer em um esquema modular composto por um núcleo comum e um módulo sequencial, sendo chamado de "esquema $2+2$ " (Araujo \& Vianna, 2010). 
Da mesma forma que os cursos anteriormente citados, a disciplina de química, com a reforma de 1931, passa a ser obrigatória nas duas séries finais do curso ginasial e nas duas séries do curso científico para o ingresso nos cursos superiores de medicina, farmácia, odontologia, engenharia e arquitetura. Assim, atendendo a essa demanda, os primeiros cursos de Química foram criados em 1934 na Universidade de São Paulo (USP), e em 1935 na Universidade do Distrito Federal (UDF). Porém, o formato dos cursos ofertados era bastante focado para a formação de bacharéis, e a didática ficava restrita ao último ano da formação, conforme o "modelo 3+1" (Lima \& Leite, 2018; Osório, 2009).

A expansão dos cursos de Química foi um processo ainda mais lento do que o das universidades no Brasil, uma vez que sua implantação e funcionamento eram considerados bastantes custosos. Porém, é no cenário pós-Segunda Guerra, do boom da industrialização e do desenvolvimento científico e tecnológico, que as necessidades de incorporação dos conhecimentos construídos influenciaram os currículos escolares (Chassot, 2004). Para tal, exigiu-se um maior número de professores da área das ciências, influenciando o número de cursos ofertados para a formação destes professores.

A partir de então, o curso de licenciatura em química foi ajustado conforme as diretrizes vigentes, assim como as demais licenciaturas. Mas é com a LDB/1996 e a Resolução CNE/CP N. 01/2002 que o curso de licenciatura em Química passou a ter uma estrutura e currículo próprios, diferente do bacharelado.

Embora tenham sido pensados e planejados em uma época aproximada, os cursos de licenciatura em Ciências Biológicas, em Física e em Química, foram desenvolvidos de forma independente. Cabe salientar que essas primeiras licenciaturas eram formuladas ainda com caráter bastante tecnicista. Esse modelo de formação perdurou até muito recentemente, quando em 2002, o fundamento da formação de professores passou a ser a epistemologia da prática, atribuindo diferentes características aos mesmos.

\section{Resoluções que Norteiam as Licenciaturas em Ciências Biológicas, em Física e em Química}

As Diretrizes Curriculares Nacionais para a formação de professores consistem em um documento no qual estão descritas as normas gerais para os cursos de formação de professores em nível superior. Embora as DCN sejam normas, garantem uma certa autonomia à instituição na elaboração de seu currículo. São documentos importantes, pois sistematizam e embasam a elaboração dos currículos, dos PPC de licenciatura, bem como de seus critérios mínimos.

A Resolução CNE/CP N. 01/2002 institui as Diretrizes Curriculares Nacionais para a Formação de Professores da Educação Básica, em nível superior, em curso de licenciatura, de graduação plena. Essa define que a prática, na matriz curricular, não poderá ficar restrita ao Estágio, deverá estar presente desde o início do curso e permear toda a formação, estando no interior de disciplinas específicas e pedagógicas. Já o Estágio Curricular Supervisionado (ECS) realizar-se-á em escola de Educação Básica e deve ser desenvolvido a partir do início da segunda metade do curso.

A Resolução CNE/CP N. 02/2002 estabelece que a carga horária para os cursos de Formação de Professores da Educação Básica, em nível superior, em curso de licenciatura plena, terá pelo menos 2.800 (duas mil e oitocentas) horas, obedecidos 200 (duzentos) dias letivos por ano em, no mínimo, 3 (três) anos letivos, com as seguintes dimensões dos componentes comuns:

I - 400 (quatrocentas) horas de prática como componente curricular, vivenciadas ao longo do curso;

II - 400 (quatrocentas) horas de estágio curricular supervisionado a partir do início da segunda metade do curso;

III - 1800 (mil e oitocentas) horas de aulas para os conteúdos curriculares de natureza científicocultural;

IV - 200 (duzentas) horas para outras formas de atividades acadêmico-científico-culturais. (Brasil, 2002, p. 1)

A Resolução CNE/CP N. 02/2015 define as Diretrizes Curriculares Nacionais para a formação inicial em nível superior 
(cursos de licenciatura, cursos de formação pedagógica para graduados e cursos de segunda licenciatura) e para a formação continuada. Segundo essa Resolução, a carga horária deve estar distribuída da seguinte maneira:

[...] no mínimo, 3.200 (três mil e duzentas) horas de efetivo trabalho acadêmico, em cursos com duração de, no mínimo, 8 (oito) semestres ou 4 (quatro) anos, compreendendo:

I - 400 (quatrocentas) horas de prática como componente curricular, distribuídas ao longo do processo formativo;

II - 400 (quatrocentas) horas dedicadas ao estágio supervisionado, na área de formação e atuação na educação básica, contemplando também outras áreas específicas, se for o caso, conforme o projeto de curso da instituição;

III - pelo menos 2.200 (duas mil e duzentas) horas dedicadas às atividades formativas estruturadas pelos núcleos definidos nos incisos I e II do artigo 12 desta Resolução, conforme o projeto de curso da instituição;

IV - 200 (duzentas) horas de atividades teórico-práticas de aprofundamento em áreas específicas de interesse dos estudantes, conforme núcleo definido no inciso III do artigo 12 desta Resolução, por meio da iniciação científica, da iniciação à docência, da extensão e da monitoria, entre outras, consoante o projeto de curso da instituição. (Brasil, 2015, p. 11)

Antes de caracterizarmos a Resolução CNE/CP N. 02/2019 cabe fazermos algumas ressalvas. Essa diretriz não é chamada de DCN como as demais, e sim como BNC-Formação. Ademais, tal Resolução foi amplamente criticada pelas associações e entidades preocupadas com a formação de professores pela forma aligeirada com que foi construída e pela falta de discussões a respeito de seu conteúdo (Lopes et al., 2021).

Quanto à estruturação curricular dos cursos de Formação Inicial de Professores, a Resolução CNE/CP N. 02/2019 orienta o mínimo de 3.200 horas para o desenvolvimento das competências profissionais. Essa carga horária está dividida em três grupos:

Grupo I: 800 (oitocentas) horas para a base comum que compreende os conhecimentos científicos, educacionais e pedagógicos e fundamentam a educação e suas articulações com os sistemas, escolas e práticas educacionais.

Grupo II: 1.600 (mil e seiscentas) horas para a aprendizagem dos conteúdos específicos das áreas, componentes, unidades temáticas e objetos de conhecimento da BNCC e para o domínio pedagógico desses conteúdos.

Grupo III: 800 (oitocentas) horas para a prática pedagógica com a seguinte distribuição: 400 (quatrocentas) horas de estágio e 400 (quatrocentas) horas para os componentes curriculares dos Grupos I e II, das quais:

- 400 (quatrocentas) horas de estágio supervisionado, em situação real de trabalho em escola, segundo o Projeto Pedagógico do Curso (PPC) da instituição formadora;

- 400 (quatrocentas) horas de práticas nos componentes curriculares dos Grupos I e II, distribuídas ao longo do curso, desde o seu início, segundo o PPC da instituição formadora. (Brasil, 2019, p. 23)

A seguir apresentamos, para facilitar a visualização e compreensão, um quadro resumo das Resoluções CNE/CP N.

$02 / 2002,02 / 2015$ e $02 / 2019$. 
Quadro 1: Quadro resumo das Resoluções.

\begin{tabular}{|c|c|c|c|}
\hline & Resolução CNE/CP \\
N.02/2002 & $\begin{array}{c}\text { Resolução CNE/CP } \\
\text { N.02/2015 }\end{array}$ & $\begin{array}{c}\text { Resolução CNE/CP } \\
\text { N.02/2019 }\end{array}$ & $400 \mathrm{~h}$ \\
\hline Carga Horária da PCC & $400 \mathrm{~h}$ & $400 \mathrm{~h}$ & $400 \mathrm{~h}$ \\
\hline Estágio Curricular & $400 \mathrm{~h}$ & $400 \mathrm{~h}$ & $800 \mathrm{~h}+1600 \mathrm{~h}$ \\
\hline Carga Horária das Atividades Formativas & $1.800 \mathrm{~h}$ & $2.200 \mathrm{~h}$ & $*$ \\
\hline Atividades teórico-práticas de aprofundamento & $200 \mathrm{~h}$ & $200 \mathrm{~h}$ & $*$ \\
\hline Mínimo de semestres/Anos & $--/ 3$ anos & 8 semestres/4 anos & $3200 \mathrm{~h}$ \\
\hline
\end{tabular}

Legenda: Critérios não estabelecidos na Resolução. Fonte: Autoras (2021).

Diante disso, pretendemos discorrer sobre as políticas educacionais para formação docente, com especial destaque para as políticas curriculares e os seus impactos nos cursos de licenciaturas, na área de Ciências da Natureza. Objetivamos, por meio de análise dos PPC em relação às Resoluções, identificar avanços e retrocessos para essa formação.

\section{Percursos Metodológicos}

O trabalho proposto, inspira-se em uma pesquisa qualitativa, que tem característica descritiva e "os pesquisadores tendem a analisar seus dados indutivamente" (Kauark, Manhães \& Medeiros, 2010, p. 26). Além disso, é descrita como pesquisa documental, pois "vale-se de materiais que não receberam ainda um tratamento analítico, ou que ainda podem ser reelaborados de acordo com os objetos de pesquisa" (Gil, 2002, p.45).

Para análise dos dados foi utilizada a Análise de conteúdo, que é

Um conjunto de técnicas de análise das comunicações visando obter por procedimentos sistemáticos e objetivos de descrição do conteúdo das mensagens indicadores (quantitativos ou não) que permitam a inferência de conhecimentos relativos às condições de produção/recepção (variáveis inferidas) dessas mensagens. (Bardin, 2016, p. 48)

Esse tipo de análise é constituída por três etapas: a pré-análise, a exploração do material e o tratamento dos resultados. A pré-análise tem como objetivo sistematizar/organizar os dados. Já a exploração do material é o momento em que é realizada a codificação dos dados obtidos. Por fim, o tratamento dos resultados consiste na análise, a qual deve extrapolar a descrição, buscando acrescentar algo à discussão já existente sobre o assunto (Bardin, 2016).

Para o desenvolvimento deste trabalho utilizamos como fonte de dados os Projetos Pedagógicos dos Cursos de Licenciatura em Ciências Biológicas, em Física e em Química da Universidade Federal de Santa Maria (UFSM), campus Santa Maria. Buscamos analisar os seguintes aspectos: Estágio Curricular Supervisionado (ECS), Atividades Complementares de Graduação (ACG), Prática como Componente Curricular (PCC) e Carga Horária Total do curso (CHt). Para tanto, traçamos o seguinte percurso: 1) Recolha de PPC vigente no site da UFSM; 2) Elaboração de um quadro para coleta de informações; 3) Leitura dos PPC para coleta de informações, a partir do quadro preestabelecido; 4) Organização e tratamento das informações coletadas; 5) Construção e interpretação dos resultados. 
Os três cursos escolhidos são ofertados no período diurno pelo Centro de Ciências Naturais e Exatas (CCNE) da UFSM. Tal universidade é considerada uma importante instituição de Ensino Superior, principalmente por ser a primeira universidade federal localizada no interior do estado do Rio Grande do Sul. No CCNE são alocados treze cursos de graduação e quatorze de pós-graduação, sendo um dos maiores centros da instituição. Além disso, a UFSM e o CCNE fazem parte do histórico acadêmico e cotidiano destas pesquisadoras.

\section{Análise e Discussão dos Resultados}

No Quadro 2 apresentamos os dados obtidos a partir dos PPC, quanto à distribuição de carga horária das disciplinas referentes ao ECS, à PCC, às ACG, e à CHt.

Quadro 2: Dados dos Cursos de Licenciatura na UFSM obtidos através dos PPC.

\begin{tabular}{|c|c|c|c|}
\hline & Ciências Biológicas & Física & Química \\
\hline PPC vigente & 2019 & 2005 & 2019 \\
\hline \multirow{3}{*}{ Estágio } & $405 \mathrm{~h}$ & $405 \mathrm{~h}$ & $420 \mathrm{~h}$ \\
\hline & $\begin{array}{l}\text { escolas de educação básica da } \\
\text { sede do município de Santa } \\
\text { Maria; excepcionalmente, o } \\
\text { Centro de Educação da UFSM }\end{array}$ & Espaço formal (escolas) & $\begin{array}{c}\text { Espaços formais } \\
\text { Cursos educacionais (EJA, SESI, } \\
\text { SENAC); } \\
\text { Organizações nas abrangências da } \\
\text { UFSM que requerem ensino de } \\
\text { química; } \\
\text { Outros locais educacionais de } \\
\text { formação em Nível Fundamental e } \\
\text { Médio. }\end{array}$ \\
\hline & $5^{\circ}$ ao $8^{\circ}$ semestre & $5^{\circ}$ ao $8^{\circ}$ semestre & $5^{\circ}$ ao $8^{\circ}$ semestre \\
\hline \multirow{3}{*}{ PCC* } & $405 \mathrm{~h}$ & $405 \mathrm{~h}$ & $435 \mathrm{~h}$ \\
\hline & Ped; Esp & Excl. & Ped; Esp; Excl. \\
\hline & A partir do $2^{\circ}$ semestre & do 3 ao $6^{\circ}$ semestre & $\begin{array}{c}\text { do } 1^{\circ} \text { ao } 8^{\circ} \text { semestre, com exceção do } \\
3^{\circ} \text { semestre }\end{array}$ \\
\hline ACG & $200 \mathrm{~h}$ & $240 \mathrm{~h}$ & $120 \mathrm{~h}$ \\
\hline CHtotal & $3.350 \mathrm{~h}$ & $3.120 \mathrm{~h}$ & $3.360 \mathrm{~h}$ \\
\hline
\end{tabular}

Legenda: *PCC pode ocorrer em disciplinas pedagógicas (Ped), disciplinas específicas (Esp) ou ter uma disciplina exclusiva para desenvolver a PCC (Excl). Fonte: Autores (2021).

Inicialmente, salientamos que, apesar dos três cursos pertencerem à mesma instituição, a configuração e organização do PPC é diversificada. Nos cursos que compreendem nossa análise, essa diversificação resulta em uma dificuldade em encontrarmos e coletarmos os dados, principalmente no que tange às PCC. Ainda que a UFSM possua em seu Projeto Pedagógico Institucional (PPI) a estrutura mínima exigida dos PPC, a autonomia organizacional dos cursos implica na multiplicidade de estruturações curriculares.

A respeito do curso de Licenciatura em Física, analisamos a sua organização de acordo com a Resolução CNE/CP N. 02/2002, visto que o seu PPC está em consonância com essa, não tendo, assim, sido atualizado para Resolução CNE/CP N. 02/2015 ou Resolução CNE/CP N. 02/2019. Dessa forma, o curso encontra-se em desatualização com a atual política nacional 
de formação de professores.

Em relação ao ECS, observamos que a realização do mesmo está em consonância com o proposto pela Resolução CNE/CP N. 02/2002, pois prevê 405 horas para sua efetivação, sem pré-requisitos previstos no PPC. Além disso, sua organização segue o previsto na referida Resolução, estando devidamente alocado na segunda metade do curso, do $5^{\circ}$ ao $8^{\circ}$ semestre, devendo ser realizado obrigatoriamente em ambientes formais de ensino (escolas).

Quanto às PCC, nossa análise demonstrou que o curso atende às normas da Resolução, uma vez que dedica 405 horas para a realização das mesmas. A distribuição da carga horária ocorre ao longo do curso, sendo vivenciadas entre o $3^{\circ}$ e o $6^{\circ}$ semestre, com desenvolvimento por meio de disciplinas específicas, cuja carga horária é dedicada, em sua totalidade, a componentes práticos, a saber: Instrumentação para o Ensino de Física A, B, C, D e Unidades de Conteúdo de Física I e II. No PPC não é especificado onde deve ocorrer a PCC, contudo o documento salienta que

serão adotadas práticas pedagógicas compatíveis com um envolvimento crescente do aluno nas atividades didáticas e com as escolas da rede de ensino médio, com ênfase na escola em que o mesmo realizará seu estágio supervisionado" (Universidade Federal de Santa Maria, 2005, np)

Ainda, enfatizamos aqui que, quando esse curso optar pela reestruturação curricular, não seguirá mais as orientações da Resolução CNE/CP N. 02/2015, mas sim deverá orientar-se pela Resolução CNE/CP N. 02/2019 que está em vigência. Assim, ampliando a sua carga horária total de 3.120 horas para no mínimo 3.200 horas distribuídas segundo a BNC-Formação.

Podemos notar então, que egressos desse curso, têm uma formação defasada em relação às Resoluções de formação de professores. Isso leva a uma disparidade entre o que se espera da formação de um professor de Física para atuar no Ensino Médio, o "perfil esperado", e aquele formado nos cursos de licenciatura, o "perfil pretendido" (Pinheiro \& Massoni, 2021), tal como o curso de Física analisado neste trabalho. Esses perfis concordam em muitos aspectos, porém, o que mais chama atenção é que esse professor "esperado" e "pretendido" é pensado como um super herói, demonstrando que os documentos oficiais não consideraram o ponto de vista do próprio educador.

Terrazzan et al. (2008) ao analisar os cursos de Licenciatura em Ciências Biológicas, em Física e em Química quanto à sua adequação à Resolução CNE/CP N. 02/2002, chegaram às mesmas observações apresentadas por nós em relação ao curso de Licenciatura em Física da UFSM. Nesse sentido, percebemos que, embora 13 anos tenham se passado e a publicação de duas novas Resoluções tenham ocorrido, o curso continua com a mesma configuração curricular, ou seja, não sofreu nenhuma atualização ou adequação com as novas diretrizes vigentes.

No que tange a análise do PPC do curso de Licenciatura em Ciências Biológicas da UFSM, ressaltamos que o mesmo foi publicado em 2019, e, portanto, segue as normativas da Resolução CNE/CP N. 02/2015. A carga horária total do curso compreende 3.350 horas e exige a realização de 200 horas de ACG, cumprindo o determinado na referida Resolução.

Os momentos de ECS deste curso podem ser executados em "escolas de educação básica da sede do município de Santa Maria; excepcionalmente, o Centro de Educação da UFSM" (Universidade Federal de Santa Maria, 2019, np), conforme o PPC do curso. A respeito do ECS, seu desenvolvimento perfaz 405 horas que devem ocorrer entre o $5^{\circ}$ e $8^{\circ}$ semestre, correspondendo à segunda metade do curso.

Os pré-requisitos previstos para o Estágio Curricular Supervisionado das Ciências Biológicas 1, referente à primeira etapa do ECS que ocorre no Ensino Fundamental são: Fundamentos de Evolução Biológica, Biologia Celular B, Biologia Celular e Molecular Experimental, Biodiversidade, Fundamentos da Microbiologia B, Biologia e Sociedade, Biologia do Desenvolvimento e Embriologia e Zoologia I B. Além destas, são exigidas seis disciplinas como co-requisitos, disciplinas que devem ser cursadas concomitantemente ao ECS. Para o Estágio Curricular Supervisionado das Ciências Biológicas 2, referente 
à segunda etapa do ECS no Ensino Fundamental, são exigidas as disciplinas: Políticas Públicas e Gestão na Educação Básica, Estágio Curricular Supervisionado das Ciências Biológicas 1 e Didática das Ciências Biológicas 2. Para a execução dessa etapa, são estabelecidos seis co-requisitos.

Já para o Estágio Curricular Supervisionado das Ciências Biológicas 3, correspondente ao primeiro estágio em Nível Médio, não possui pré-requisitos, mas apresenta sete disciplinas co-requisitadas. No segundo e último estágio em Nível Médio, o Estágio Curricular Supervisionado das Ciências Biológicas 4, faz-se presente como pré-requisito as disciplinas de: Estágio Curricular Supervisionado das Ciências Biológicas 3, Didática das Ciências Biológicas 2, Políticas Públicas e Gestão na Educação Básica, Psicologia da Educação B, Estágio Curricular Supervisionado das Ciências Biológicas 1 e Tópicos Transversais para a Formação Docente I. Ademais, são exigidos três co-requisitos.

Ressaltamos que dentre os conjuntos de disciplinas exigidas para a realização dos ECS no curso de Licenciatura em Ciências Biológicas da UFSM, encontramos disciplinas que "agrupam conhecimentos e conteúdos curriculares que atentam para o saber ensinar. $\mathrm{O}$ foco da formação docente para o ensino de ciências e biologia é contemplado, com maior precisão, em seu interior" (Medeiros e Medeiros, 2020, p. 1987). Essas disciplinas são, ao nosso ver, fundamentais pois contribuem para a preparação para o ECS, para além do conteúdo específico da área.

Sobre a PCC, destacamos que a carga horária total exigida para este curso é de 405 horas, que devem ser desenvolvidas a partir do segundo semestre do curso. A PCC é desenvolvida em disciplinas específicas da área do conhecimento e em disciplinas pedagógicas, em concordância com o que é exposto pela Resolução CNE/CP N. 02/2015.

De modo geral, o PPC do curso de Licenciatura em Ciências Biológicas da UFSM atende a Resolução CNE/CP N. 02/2015, como observado por Boton (2019) ao analisar cursos de Licenciatura em Ciências Biológicas do Brasil. Tendo em vista que logo após a publicação deste PPC, em 2019, ocorreu a publicação da Resolução CNE/CP N. 02/2019, o curso deverá sofrer alterações muito em breve, para atender à referida resolução, principalmente no que tange a organização de acordo com as competências e habilidades previstas na BNC-Formação.

A análise realizada acerca da constituição do PPC do curso de Licenciatura em Química ocorreu em comparação com a Resolução CNE/CP N. 02/2015. Em relação à duração do curso, a Licenciatura em Química também se encontra de acordo com essa Resolução ao totalizar 3.360 horas. Dos demais critérios preestabelecidos na tabela anterior, podemos observar em relação aos ECS que o mesmo se encontra em consonância com a referida Resolução quanto a sua carga horária, compreendendo 420 horas. Em uma investigação mais aprofundada no PPC, percebemos que na grade curricular do curso os ECS encontram-se estruturados do $5^{\circ}$ ao $8^{\circ}$ semestre, com pré-requisitos estabelecidos aos licenciandos para que possam desenvolver esse componente.

Dos requisitos estipulados para o Estágio de Ciências A e Estágio de Ciência B, respectivos ao Nível Fundamental, encontram-se a exigência de se ter cursado o $1^{\circ}$ semestre completo, além de ter a aprovação nas disciplinas de Metodologia do Ensino de Ciências, Introdução a Biologia e Políticas Públicas e Gestão na Educação Básica A. Para o Estágio de Química A e Estágio de Química B, correspondentes ao Nível Médio, estabelece-se como critérios a aprovação nas disciplinas de Cálculo A, Física I e Metodologia do Ensino de Química.

Ressaltamos que tais diretivas estimadas no PPC se devem ao fato que a Resolução CNE/CP N. 02/2015 não apresenta em qual momento do curso o ECS deve ser ofertado. Embora a referida Resolução permita interpretações de que o ECS possa ocorrer em qualquer momento do curso, pela exigência dessas disciplinas, se entende que este momento se encontra a partir da segunda metade do curso, visto que os pré-requisitos devem ser feitos anteriormente. Fato esse, também observado no curso de Ciências Biológicas, no qual os conjuntos de requisitos preparam os licenciandos para a realização do ECS, transcendendo os conteúdos específicos da matéria de ensino propriamente ditos. 
Sobre os espaços para a realização dos ECS, os licenciandos em química possuem um amplo espaço para atuação, dos quais percebe-se predomínio ou exclusividade de ambientes formais. Isto é posto, pois nas classificações "Organizações da comunidade na abrangência da UFSM que apresentem demandas por situações de Educação em Química" e "Outros locais que apresentem atividades educacionais de formação em nível Fundamental, Médio ou equivalente" (Universidade Federal de Santa Maria, 2019, np). Não há um esclarecimento de quais ambientes as mesmas se referem, sendo passível de interpretação.

Com relação a PCC, observamos que esta, assim como os ECS, tem sua carga horária correspondente ao preconizado na Resolução CNE/CP N. 02/2015, compreendendo 435 horas. Neste sentido, sua organização encontra-se estruturada no decorrer do curso, dentro de disciplinas pedagógicas, disciplinas específicas e ainda em disciplinas exclusivas, estando ausente apenas no $3^{\circ}$ semestre.

Sobre este aspecto, o curso de Química ampliou a abrangência das disciplinas relacionadas à PCC na graduação dos licenciandos quando comparamos com o estudo realizado por Terrazan et al. (2008), em que essa era inserida apenas como parte da carga horária de algumas disciplinas específicas e de disciplinas pedagógicas. A escolha dessa incorporação encontra-se em consonância com o Parecer CNE/CES N. 15/2005, no qual é determinado que essa pode ser desenvolvida

[...] como núcleo ou como parte de disciplinas ou de outras atividades formativas. Isto inclui as disciplinas de caráter prático relacionadas à formação pedagógica, mas não aquelas relacionadas aos fundamentos técnico-científicos correspondentes a uma determinada área do conhecimento (Brasil, 2015, p.3).

Sobre as ACG, observamos que há uma redução do número de horas estipulados pela DCN de 2015, a qual determina que os PPC das licenciaturas devem destinar 200 horas para tais atividades. No entanto, no PPC analisado, estabeleceu-se às ACG apenas 120 horas, uma redução significativa de critérios formativos, os quais são compreendidos por Marafão, Gluitz e Santos-Tonial (2015) como importantes para o enriquecimento do processo de ensino e aprendizagem dos estudantes. De acordo com os autores as atividades complementares inserem o estudante em atividades de formação social, humana, cultural e científica, os quais contribuem substancialmente na formação profissional de todos os acadêmicos (Marafão, Gluitz \& Santos-Tonial, 2015).

\section{Considerações Finais}

Primeiramente, consideramos que a existência de diferentes estruturas curriculares nos três cursos analisados, mesmo que tenha dificultado a análise dos documentos, é primordial. Visto que, ressalta a autonomia existente no interior das universidades, permitindo aos cursos organizarem-se de forma independente, ainda que respeitem os critérios mínimos exigidos no PPI da instituição.

Percebemos que os cursos de Licenciatura em Física e em Química estão parcialmente em consonância com as Resoluções CNE/CP N. 02/2002 e N. 02/2015, respectivamente, enquanto o curso de Ciências Biológicas respeita as exigências da Resolução CNE/CP N. 02/2015. Apesar disso, os três cursos encontram-se em descompasso quanto à Resolução CNE/CP N. 02/2019, vigente no momento em que esse artigo foi elaborado.

O que pudemos observar é que a Licenciatura em Física da UFSM apresenta um descompasso ao que tange às duas resoluções posteriores à publicação do PPC (02/2015 e 02/2019), pois é o único desta análise que ainda segue a Resolução 02/2002. Desse modo, acreditamos que é inadiável a atualização do PPC do curso de Licenciatura em Física, em virtude do desejo de uma formação de professores cada vez mais atualizados e aperfeiçoados às demandas do contexto social, político e cultural.

Quanto aos cursos de Licenciatura em Ciências Biológicas e em Química, reiteramos sua compatibilidade com a Resolução CNE/CP N. 02/2015, com exceção da carga horária dedicada às ACG no caso da Licenciatura em Química, que é 
inferior ao exigido legalmente. Ao compararmos essa característica com o observado em estudos anteriormente realizados, fica claro o avanço em comparação aos PPC anteriores, demonstrando o cuidado e interesse em aprimorar a formação de professores. Considerando a publicação da Resolução CNE/CP N. 02/2019, os cursos deverão sofrer alterações muito em breve, para atender à exigência de organização curricular segundo a lógica de competências e habilidades previstas pela BNC-Formação.

Destacamos que em todos os cursos, o ECS é limitado aos espaços formais de educação, desconsiderando, mesmo que quando possível, os espaços não formais. Inúmeras pesquisas apontam a importância significativa dos espaços não formais de ensino, não apenas como espaço de aprendizagem para alunos da Educação Básica, mas também para a formação de professores, visto a gama de locais que os licenciandos podem atuar, como museus, jardins botânicos, planetários, mantenedores, entre outros. Esses espaços são possibilidades de atuação profissional de docentes e deveriam receber a mesma preocupação de inserção no âmbito formativo dos futuros professores, sendo talvez um aspecto a ser repensado nas políticas públicas de formação de professores.

Destacamos que o presente estudo não se esgota aqui, visto que os três cursos analisados devem se adequar à Resolução CNE/CP N. 02/2019, vigente no momento em que esse artigo foi elaborado. Pretendemos que assim que os cursos se atualizarem, analisar suas adequações e mudanças a respeito da formação de professores nos PPC destes cursos.

Por fim, o que enfatizamos com esse trabalho, podemos caminhar a um avanço na formação de professores. E que para que tenhamos professores super heróis tão desejados no mundo atual, devemos incentivar e focar em desenvolver um PPC melhor e diversificado. Sendo assim, que atenda a todas as demandas do século XXI, considerando os princípios de equidade, tais como, as questões socioambientais, éticas, estéticas e relativas à diversidade étnico-racial, de gênero, sexual, religiosa, de faixa geracional e sociocultural.

\section{Referências}

Amestoy, M. B., Rigue, F. M., \& Gonçalves, D. F. (2021). A BNCC e a formação de professores: políticas, contextos e (des) alinhamentos. In: Rigue, F. M.; Oliari, G.; Sturza, R. (Org.). Fios invisíveis em educação II, (2a ed.) Veranópolis: Diálogo Freiriano, 175-199.

Araujo, R. S. \& Vianna, D. M. 2010. A história da legislação dos cursos de Licenciatura em Física no Brasil: do colonial presencial ao digital a distância. Revista Brasileira de Ensino de Física, 32 (4), 4403. https://repositorio.ufba.br/ri/bitstream/ri/3495/1/10.pdf.

Ayres, A. C. B. M. (2005). Tensão entre matrizes: um estudo a partir do curso de Ciências Biológicas da faculdade de Formação de Professores/ UERJ. Tese de Doutorado, Universidade Federal Fluminense, Niterói, Rio de Janeiro, Brasil.

Bardin, L. (2016). Análise de conteúdo. Edições 70.

Boton, J. M. Demandas e dilemas da Prática como Componente Curricular na Formação de Professores de Biologia. 2019. Tese (Doutorado em Educação em Ciências) Programa de Pós-Graduação Educação em Ciências: Química da Vida e Saúde. Universidade Federal de Santa Maria. Santa Maria, RS, 2019.

Brasil. (1996). Lei 9394 de 20 de dezembro de 1996. (1996). Estabelece as diretrizes e bases da educação nacional. Brasília, DF. http://www.planalto.gov.br/ccivil_03/leis/19394.htm.

Brasil. (2002). Conselho Nacional de Educação. Conselho Pleno. (2002). Resolução CNE/CP 1, de 18 de fevereiro de 2002. Institui Diretrizes Curriculares Nacionais para a Formação de Professores da Educação Básica, em nível superior, curso de licenciatura, de graduação plena. Brasília. http://portal.mec.gov.br/cne/arquivos/pdf/rcp01_02.pdf.

Brasil. (2001). Conselho Nacional de Educação. (2001). Resolução N. 2, de 11 de setembro de 2001. Institui as Diretrizes Nacionais para a Educação Especial na Educação Básica. Brasília, Diário Oficial da União, seção 1E: 39-40. http://portal.mec.gov.br/seesp/arquivos/pdf/res2_b.pdf.

Brasil. (2002). Conselho Nacional de Educação. Conselho Pleno. (2002). Resolução CNE/CP 02, de 19 de fevereiro de 2002. Institui a duração e a carga horária dos cursos de licenciatura, de graduação plena, de formação de professores da Educação Básica em nível superior. Diário Oficial da União, Seção 1: 9. http://portal.mec.gov.br/cne/arquivos/pdf/CP022002.pdf.

Brasil. (2015). Conselho Nacional de Educação. Conselho Pleno. (2015). Resolução CNE/CP N. 02/2015, de $1^{\circ}$ de julho de 2015. Define as Diretrizes Curriculares Nacionais para a formação inicial em nível superior (cursos de licenciatura, cursos de formação pedagógica para graduados e cursos de segunda licenciatura) e para a formação continuada. Diário Oficial da União, seção 1, 124: 8-12. http://portal.mec.gov.br/docman/agosto-2017-pdf/70431-res-cne-cp002-03072015-pdf. 
Brasil. (2019). Conselho Nacional de Educação. Conselho Pleno. (2019). Resolução CNE/CP N. 2, de 20 de dezembro de 2019. Define as Diretrizes Curriculares Nacionais para a Formação Inicial de Professores para a Educação Básica e institui a Base Nacional Comum para a Formação Inicial de Professores da Educação Básica (BNC-Formação). Diário Oficial da União, seção: 1: 46. http://portal.mec.gov.br/docman/dezembro-2019-pdf/135951-rcp002-19/file.

Brasil. (2005). Conselho Nacional de Educação. Câmara de Educação Superior. (2005). Parecer CNE/CES N ${ }^{o}$. 15/2005. Solicitação de esclarecimento sobre as Resoluções CNE/CP N. 1/2002, que institui Diretrizes Curriculares Nacionais para a Formação de Professores da Educação Básica, em nível superior, curso de licenciatura, de graduação plena, e 2/2002, que institui a duração e a carga horária dos cursos de licenciatura, de graduação plena, de Formação de Professores da Educação Básica, em nível superior. http://portal.mec.gov.br/cne/arquivos/pdf/pces0015_05.pdf.

Chassot, A. (2004). Para que(m) é útil o ensino? Alternativas para um (ensino de Química) mais crítico (2a ed.) Canoas: ULBRA.

Gil, A. C. (2002). Como elaborar projetos de pesquisa (4a ed.) Atlas.

Kauark, F., Manhães, F. C. \& Medeiros, C. H. (2010). Metodologia da pesquisa: um guia prático. Litterarum.

Krasilchik, M. (1987). O professor e o currículo das ciências. EPU/EDUSP.

Lima, J. O. G. \& Leite, L. R. (2018). Historicidade dos cursos de licenciatura no Brasil e sua repercussão na formação do professor de química. REnCiMa, 9(3), 143-162. Disponível em: http://revistapos.cruzeirodosul.edu.br/index.php/rencima/article/view/1483/1006 Acesso em: 20 jun. 2021.

Lisovski, L.A. (2006). Organização e desenvolvimento do estágio curricular na formação do professor de Biologia. Dissertação de Mestrado, Universidade Federal de Santa Maria, Santa Maria, Rio Grande do Sul, Brasil.

Lopes, A. F., Amestoy, M. B., Schmitz, G. L. \& Boton, J. M. O que se espera da BNC-Formação em relação a BNCC predisposta na Resolução N. CNE/CP 2/2019? In: AMESTOY, M. B.; FOLMER, I.; MACHADO, G. E. A BNCC em cenários atuais: currículo, ensino e a formação docente. Santa Maria: Arco editores, 2021, p. 45-58. https://www.ufsm.br/app/uploads/sites/565/2020/01/BNCC_CenariosAtuais_AMESTOY_Arco_2021.pdf.

Marafão, D., Gluitz, A. C. \& Santos-Tonial, L. (2015). Panorama dos Cursos de Licenciatura em Química ofertados pelas Instituições de Ensino Superior do Estado do Paraná. Revista Virtual de Química, 7(3), 811- 822.

Medeiros, E. A. de \& Medeiros, M. L. S. de. (2020). Licenciaturas em Ciências Biológicas: análise de currículos de formação de professores para o ensino de ciências e biologia. Revista Ibero-Americana de Estudos em Educação, 15(4), 1967-1990. https://periodicos.fclar.unesp.br/iberoamericana/article/view/13642.

Osório, V. K. L. (2009). Alameda Glette, 463, sede do Curso de Química da Universidade de São Paulo no período 1939-1965. Química Nova, 32(7), 19751980. http://www.scielo.br/pdf/qn/v32n7/49.pdf.

Pinheiro, L. A. Massoni, N. (2021). Traçando um perfil para o professor de Física da Educação Básica: o que preconiza a legislação brasileira? Revista Brasileira de Ensino de Ciências e Matemática, 4(1), 430-457.

Terrazzan, E. A., Dutra, E. F., Winch, P. G. \& Silva, A. A. da. (2008). Configurações curriculares em cursos de licenciatura e formação identitária de professores. Rev. Diálogo Educ., 8(23), 71-90.

Tomita, N. (1990). De História Natural a Ciências Biológicas. Ciência e Cultura, 47(12), 1173-1177.

Universidade Federal de Santa Maria. (2019). Projeto Político-Pedagógico do Curso de Ciências Biológicas - Licenciatura Plena. Santa Maria. https://www.ufsm.br/cursos/graduacao/santa-maria/ciencias-biologicas/projeto-pedagogico

Universidade Federal de Santa Maria. (2019). Projeto Político-Pedagógico do Curso de Química - Licenciatura Plena. Santa Maria. https://www.ufsm.br/cursos/graduacao/santa-maria/quimica/projeto-pedagogico.

Universidade Federal de Santa Maria. (2005). Projeto Político-Pedagógico do Curso de Física - Licenciatura Plena. Santa Maria. https://www.ufsm.br/cursos/graduacao/santa-maria/fisica/projeto-pedagogico. 